\title{
Evaluation of Football Pass Extraction Using the Offence/Defence Model
}

\author{
Akira Yamanaka ${ }^{1}$, Hiroshi Otsuka ${ }^{2}$, Dota Otsuka ${ }^{3}$, Shinya Ueda ${ }^{4}$, Jorge Diaz-Cidoncha \\ Garcia $^{5^{*}}$, Masahiro Sugiyama ${ }^{6}$ \\ ${ }^{1}$ Faculty of Regional Collaborative Innovation, Ehime University \\ ${ }^{2}$ Graduate School of Science and Engineering, Ehime University \\ ${ }^{3}$ Faculty of Education, Oita University \\ ${ }^{4}$ Faculty of Education, Gifu University \\ ${ }^{5}$ National Institute of Physical Education (INEF), Polytechnic University of Madrid, Fédération Internationale \\ de Football Association (FIFA) \\ ${ }^{6}$ Centre for Sport and Exercise Sciences, University of Malaya, Malaysia
}

*Corresponding Author: Jorge Diaz-Cidoncha Garcia, National Institute of Physical Education (INEF), Polytechnic University of Madrid, Fédération Internationale de Football Association (FIFA)

\begin{abstract}
In this study, the researchers attempted to restructure the offenceldefence model, applying finitestate machine (hereinafter FSM) theory to define the progression of offenceldefence status in football in mathematical terms. Furthermore, this study aimed to evaluate the validity of tactical analysis using the offenceldefence model to perform extraction and evaluation of passes from numerical location data. In comparisons of each parameter based on the F-measure, while, on the whole, recall levels are not high, the F-measure for the model with parameters shotb=7.3m/s, $r=2 m$ is high, yielding results closer to what occurred in the actual match. Due to the fact that while levels of recall were low for pass extraction using the offence/defence model, levels of precision were high, it was anticipated that the passes identified mostly did reflect actual passes.It is thought that being able to determine offenceldefence status and passes using a mathematical model will help advance analysis of teams' tactical behavior as well.

Having made one affirmation of a fusion of the charms associated with sports and the usefulness of big data (and the various technologies that make use of it), it is our hope that the efforts we have made with this research may be of some assistance in advancing the field of tactical development-one of the many charms associated with sports - through work carried out by people in the days ahead.
\end{abstract}

Keywords: offenceldefence model, objective data, mathematical model, tactical analysis

\section{INTRODUCTION}

The adoption of information technology in team sports has increased significantly in recent years, and the use of objective data has become common in sports at the highest levels. Particularly in football, the usage of objective data by professional teams for tactical analysis has expanded in various ways, also influenced by business elements. One example entails setting up cameras at a stadium to create a tracking system, which involves capturing the players' movement as location information, for the purpose of improving players' performance. Furthermore, such data is also used to produce valuable information for fans and spectators. The use of such primarily numerical objective data has great potential to influence future development in sports.

In the analysis of a football game, everything occurring in the play can be translated into numerical data by considering "who" and "where" in terms of three-dimensional spatial coordinates and adding the ball's location (1), it has been suggested, indicating the theoretical potential for quantitative and qualitative analysis of numerical game data. In recent years, there have been many reports that a framework has been established to objectively analyze and evaluate players' physical performance (2), including detailed analysis of their traveling distance and speed. Some research also reported the 
usage of a statistical method for analyzing big data $(3,4,5,6)$. Presently, much research also reports scientific approaches being taken with numerical data from football playing. Much scientific research is being conducted with big data, as described above. However, it has also been indicated that the usage and statistical analysis of this data could be further developed to improve game analysis (7). In practice, the interpretation of numerical data, particularly that with tactical aspects, has been largely entrusted to analysts with specialised knowledge. It has been pointed out that, at present, there exists no method of quantitative formation analysis (3), and research frameworks making direct usage of location data in qualitative analysis such as tactical analysis of players' or teams' plays are rarely seen.

Yamanaka et al. (8) established a Time-Restricted Dominant Region Diagram (hereinafter "TRDRD") corresponding to the area in which players have control of the ball as a model with the capacity to make determinations for the purpose of direct tactical analysis of numerical data in football matches. This provided the basis for their formulation of an offence/defence model serving as a mathematical model of tactical analysis to enable determination of the ball's state at a given time and teams' offence/defence statuses across sustained spans of time (8). In tactical analysis, determination of a team's status of ball possession - and therefore their offence/defence status - is basic and vital information for predicting players' tactical moves. tThe offence/defence model can be considered to be a mathematical model capable of direct, basic tactical analysis of a football game's numerical data. However, in tactical analysis of football, it is customary to observe the sequence of plays that take place on the playing field to determine teams' offence/defence statuses, not only the state of the ball at a certain location and point in time. Wade (9) states, "the first and most important principle in [football] is that ball possession determines everything," and illustrates the interplay between offence and defence modes on the field as a principle of team play from the perspective of team strategy (see Figure 1).

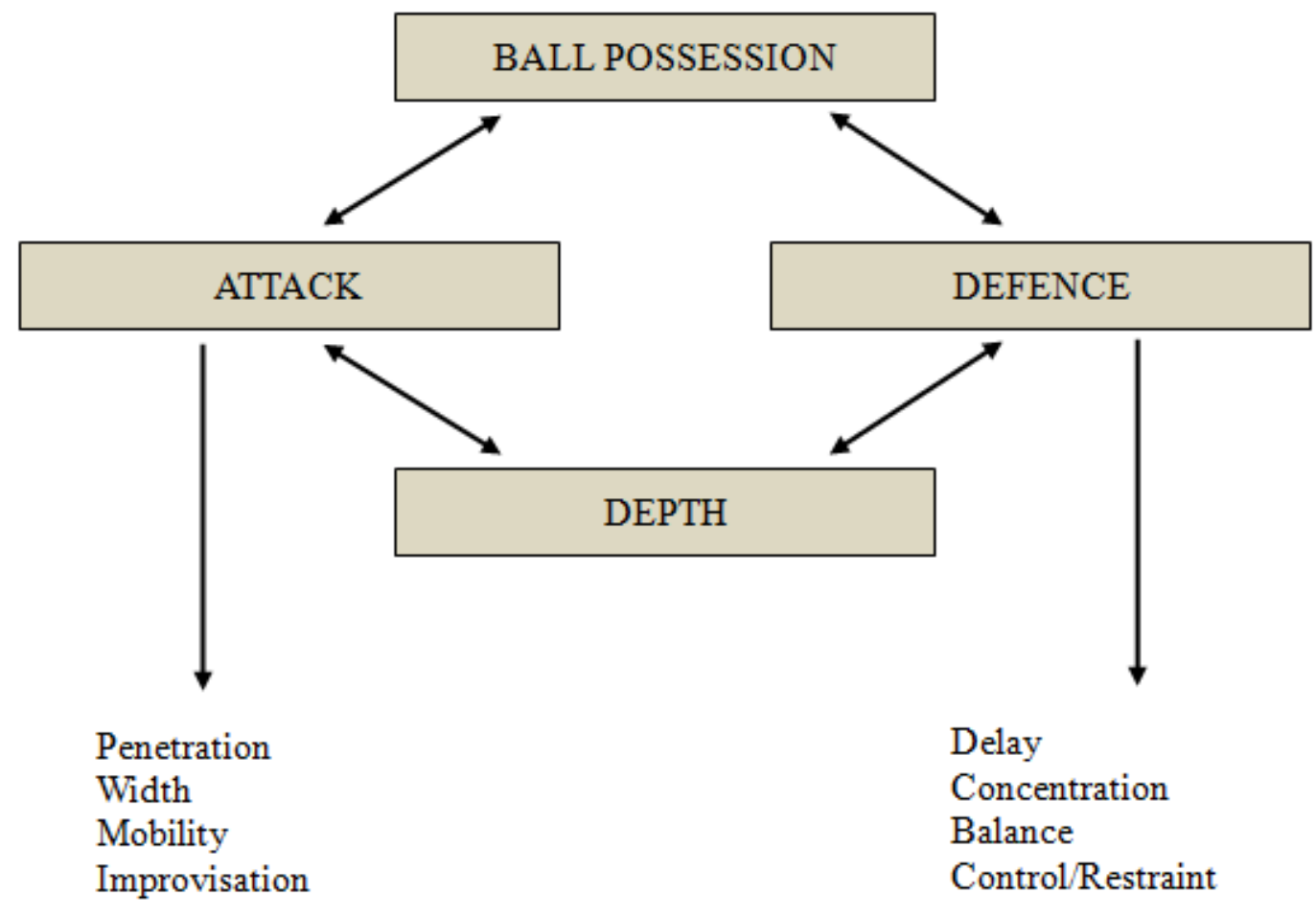

Figure1. Principle of team play

This illustrates sensible plays (moves) by each player of each team with regard to their team's offence/defence status, based on the team's status of ball possession, to construct a model of offence/defence status progression in the context of the game. This means that, in observers' determination of offence/defence status in a game, in addition to the status of ball possession in the vicinity of the ball, the progression of offence/defence status as indicated with plays (moves) made by players is taken into consideration in context. Taking into consideration such determination processes made by analysts, it can be seen that methods of determination relying on conventional offence/defence models do not currently have the capacity to capture the progression of 
offence/defence status in mathematical terms.

Accordingly, in this study, the researchers attempt to restructure the offence/defence model, applying finite-state machine (hereinafter FSM) theory to define the progression of offence/defence status in mathematical terms. Football games proceed with mixtures of situations where the status of ball possession is clear-and in turn, whether a team is in offence or defence mode - and where it is not. Furthermore, these statuses are nondeterministic - that is, their progression is not fixed-and situations where offence/defence status is clear and where it is not exist in countless combinations, a characteristic trait of the game of football. FSM theory vitally informs the process for capturing the game of football-which is considered to contain infinite combinations of situations such as offence/defence mode status - in mathematical terms, arranged on a status-by-status basis. Applying this process to define teams' offence/defence status in mathematical terms enables tactical determination of individual players' plays (moves), the ball's movement (passes) and so on, according to mathematical inference of teams' offence/defence status (tactical mode). Hence, tactical analysis of games grounded in the team play principle that "ball possession determines everything," is made possible based not only on the state surrounding the ball at a certain location and point in time, but on the circumstances of the team as a whole as well. With reference to the abovementioned methodology, this study aims to evaluate the validity of tactical analysis using the offence/defence model to perform extraction and evaluation of passes (as far as how the approach contributes to the extraction process) from numerical location data, defining passes as movement of the ball between players during periods when a team is in offence mode.

\section{MeThodology}

Figure 2 gives an overview of the research flow.

Defining the model : NFA structure

Determination of teams'

offence/defence status during sustained periods of time

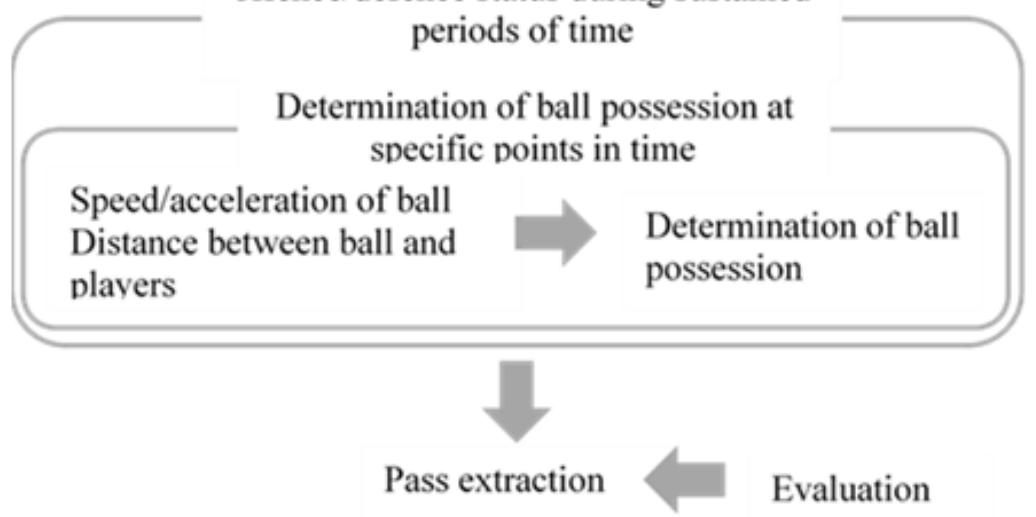

Figure 2. Evaluation of FSM structure and pass extraction

With the efforts made to advance the formulation of a mathematical offence/defence model able to determine offence/defence status from location data directly (8), it is presently possible to determine offence/defence status at certain points in a football match. However, in on-site tactical analysis of football matches or practices, the team's mode (offence/defence) at certain points in time is grasped in context based on the players' or teams' actions, and while there exists a mathematical framework to determine such a status through a logical process, the offence/defence model has not yet been mathematically clarified with the inclusion of this logical process to achieve this purpose. Accordingly, the researchers have first attempted to clarify the mathematical model applying FSM theory, as will be described in this study.

Second, the authors have attempted to perform pass extraction, applying the mathematically defined offence/defence model to analyse location data. Results were evaluated based on the numerical data used to extract the passes from a statistical perspective.

Third, the researchers examined the validity of tactical analysis using the offence/defence model based on the evaluation of pass extraction from numerical data using the clarified model. 


\section{DEFINING A MATHMATICAL OFFENCE/DEFENCE MODEL}

Numerical location data for the players and ball is used to structure an offence/defence model based on FSM theory for tactical analysis as detailed in Table 1.

Table1. Physical information obtained from location data

\begin{tabular}{|l|l|}
\hline Location data & Physical information obtained from data \\
\hline \multirow{4}{*}{ Players } & 1. Location of players on the playing field \\
\cline { 2 - 2 } & 2. Paths/distance traveled by players \\
\cline { 2 - 2 } & 3. Speed/acceleration of players' movement \\
\hline \multirow{3}{*}{ Ball } & 1. Location, path and distance traveled by the ball on the field \\
\cline { 2 - 2 } & 2. Speed/acceleration of the ball \\
\cline { 2 - 2 } & 3. Distance between players and the ball \\
\hline
\end{tabular}

Physical information from football matches such as the data points shown in Table 1 can be obtained from players' location data. While location data is produced at every moment throughout matches, qualitative information regarding a team's offence/defence mode is expressed for sustained periods of time. Therefore, the FSM for the offence/defence model was structured in the following order: 1) first, determination of which team had possession of the ball, including indeterminate cases, was made using physical location data showing the ball's speed/acceleration and its distance from players at certain moments (as shown in Table 1: rows 5 and 6), and 2) next, a team's offence/defence status during a sustained period of time was determined using ball possession information from certain points in time (see Figure 2). Finally, situations in which the ball is in motion between players of the same team during sustained periods of time when the team is in offence mode are extracted as passes (11).

\subsection{Extraction of Ball Possession}

\subsubsection{The Relationship Between Players and the Ball}

In order to determine offence/defence status based on tracking data, it is necessary to consider players who are near the ball (i.e. who have control of the ball.) This study takes the standard approach of considering a circle with a certain radius surrounding the ball to be close proximity to the ball, and a player in close proximity to the ball to be in possession of the ball. In cases when multiple players are in close proximity to the ball, however, possession of the ball is considered nondeterministic, in the sense that which player is in control of the ball is not clear.

Players' relation to the ball at specific moments, including indeterminate cases, can be determined based on the number of players in control of the ball, as defined with the following setup:
- $|\mathrm{X}|=1$
keep
- $|\mathrm{X}|>1$
mix-up
- $|X|=0$
others

The FSM on control of the ball is formed based on the above setup as shown in Figure 3. The FSM includes state transitions on control of the ball in consideration of the fact that such states undergo transitions as football matches progress.

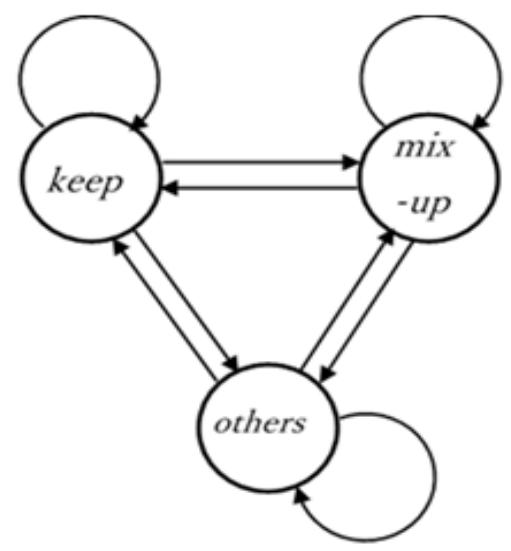

Figure 3. FSM on control of the ball 


\subsubsection{The State of the Ball Itself}

The ball's traveling speed and direction as it changes with the progression of the match can be extracted from the location data as physical information. Therefore, the finite number of states regarding whether players are involved with the ball's movement at certain points in time can be determined based on threshold levels regarding speed and direction defined as follows:

1) Players will be unable to reach the ball if the speed of the ball is greater than a certain speed $\left(\right.$ shot $\left._{b}\right)$; otherwise, there is a potential for player involvement

2) Players are considered to be involved with the ball's travel if the ball changes direction beyond a certain range (angle $\mathrm{b}_{\mathrm{b}}$ ).

Changes in the ball's speed and direction are considered to be associated with two states each, with the direct product of the two yielding an FSM with the following four states, as shown in Figure 4. The FSM's four states, $a, b, c$ and $d$ expediently represent the ball's travel speed as fast or slow and change in direction as large or small (see Table 2.) The $c$ state, representing the FSM with a reduced number of states, corresponds to a shot.

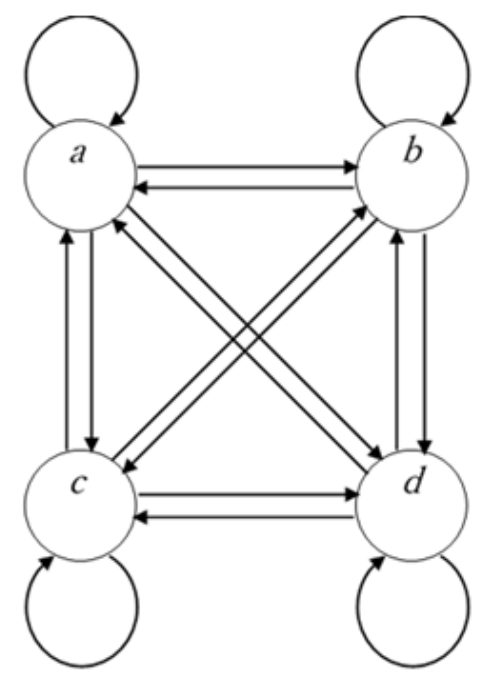

Figure 4. FSM of ball states

Table2. Combinations of ball speed and direction

\begin{tabular}{|c|c|c|}
\hline & $\begin{array}{l}\text { Speed: } \\
\text { Fast }\end{array}$ & $\begin{array}{l}\text { Speed: } \\
\text { Slow }\end{array}$ \\
\hline Change in direction: Large & $a$ & $b$ \\
\hline Change in direction: Small & $c$ & $d$ \\
\hline
\end{tabular}

\subsubsection{Ball States}

Although it would be advantageous to be able to determine the ball's state at each moment throughout the match using the direct products of the above FSMs, it is still difficult to make such qualitative determinations as the FSMs contain 12 possible states and 144 state transitions. Accordingly, the FSM of ball states was divided into two scenarios: those where players are potentially involved with the ball's movement, and those where they are not (i.e. shots), to reduce the total number of states. The FSM reduced to only two ball states is shown in Figure 5.

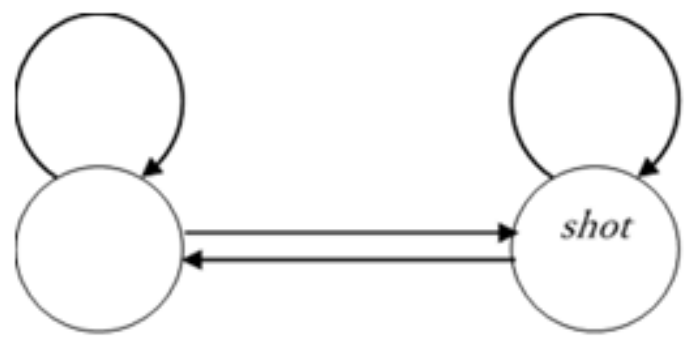

Figure 5. FSM with two ball states 
Furthermore, the direct product of the FSM on control of the ball and the FSM representing the state of the ball itself yields six states to create the following simple FSM with a reduced number of states by equating states paired with shots with those in which players have no involvement with the ball's movement (see Figure 6.)

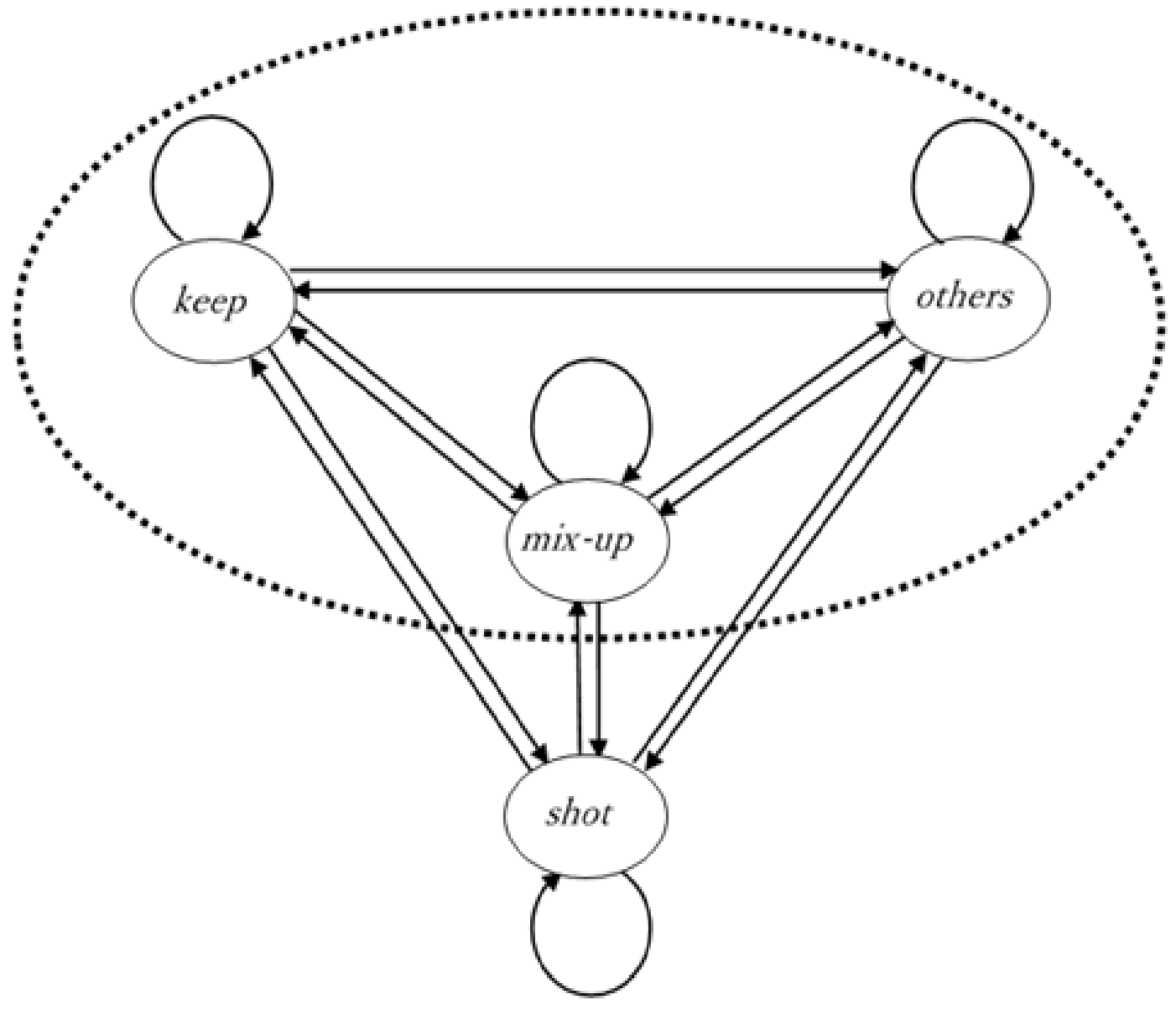

Figure 6. FSM of ball states (in combination with FSM on control of the ball)

The ball's state at time $k$ is determined with the function $\mathrm{BC}(\mathrm{k})$ as follows, based on the FSM representing ball states $(12,13)$. Each term corresponds to the previously described states.

$$
B C(k)=\left\{\begin{array}{cl}
\text { shot } \quad\left(v_{b} \geq \text { shot }_{b} \wedge\left|\theta_{b}\right| \leq \text { angle }_{b}\right) \\
\text { keep } \quad(\neg \operatorname{shot} \wedge|X|=1) \\
\text { mix }- \text { up } & (\neg \operatorname{shot} \wedge|X|>1) \\
\text { others } & (\neg \operatorname{shot} \wedge|X|=0)
\end{array}\right.
$$

$v_{b}$ represents the ball's speed, and $\theta_{b}$ represents the ball's degree of change in direction. $\neg$ shot denotes situations in which the ball is not in a "shot" state, as represented by the dotted line in Figure 6.

\subsubsection{Ball possession}

Information such as the team in possession of the ball and the position of players associated with control of the ball must be determined based not on location data, but on attributes associated with players, such as their team and position. In this study, the constants $\alpha$ and $\beta$ are used to represent teams, and information concerning which team is in possession of the ball is to be determined based on which team the player in control of the ball belongs to when the ball state is other than "shot." While situations in which players from both teams have control of the ball $(\{\alpha, \beta\})$ and in which no players have control of the ball $(\varnothing)$ are possible, such situations are collapsed into the category of indeterminate $(\varnothing)$ (see Figure 7.) 


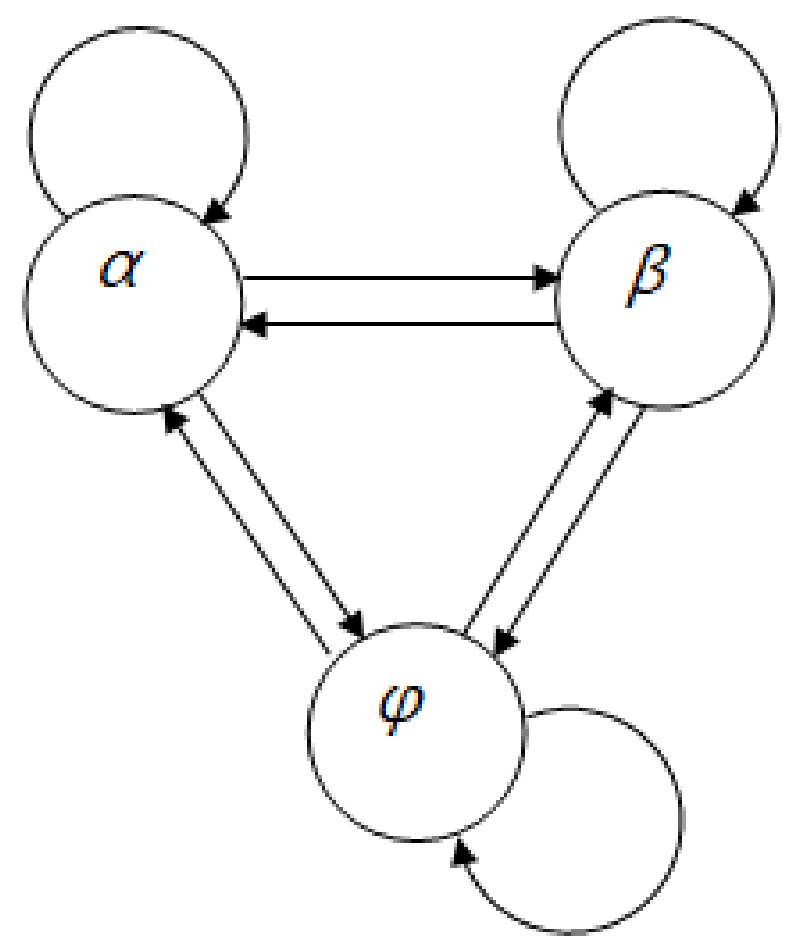

Figure7. FSM expressing ball possession

Which team is in possession of the ball at time $k$ is represented with the function $B A(k)$ as follows, based on this FSM expressing ball possession $(12,13)$.

$$
B A(k)=\left\{\begin{array}{c}
O w n(\alpha)(B C(k) \neq \operatorname{shot} \wedge \phi \neq X \subseteq \alpha) \\
\text { Own }(\beta)(B C(k) \neq \operatorname{shot} \wedge \phi \neq X \subseteq \alpha) \\
O w n(\phi)(B C(k) \neq \operatorname{shot} \wedge o . w .) \\
B A(k-1)(B C(k)=\text { shot })
\end{array}\right.
$$

If the ball is in a "shot" state, ball possession is defined on the basis of the preceding point when it was not in a "shot" state. Ball possession is given the fixed definition of $k=1$.

\subsection{Acquisition of Offence Status During a Sustained Period}

In football there are sustained periods when a team is in offence mode, and during these the ball travels between players by means of passing, dribbling and so on. Next then, a team's offence/defence status in a match during a sustained period of time is determined on the basis of the ball's state and which team is in possession of it at certain moments.

While it would be preferable if ball possession were definite at the moment of the kick and the moment the ball is received during transfer of the ball, it is not possible to simply make determinations from possession at certain points in time, since in some cases possession may be indefinite. First, if it is certain which team has possession of the ball, that team is determined to be in offence mode. If ball possession is indefinite, it is determined based on a subsequent point in time when ball possession is certain. This approach is applied to eliminate indeterminacy of states. Use of it eliminates cases in which ball possession is indefinite. Specifically it is defined with the following formula to determine which team is in offence mode at each point in time $k(13,14)$.

$$
\operatorname{isOff}(k)=\left\{\begin{array}{c}
\alpha o f f\left(\begin{array}{c}
B A(k)=O w n(\alpha) \\
\vee\left(\begin{array}{c}
B A(k)=O w n(\phi) \\
\Lambda B A(k+m)=O w n(\alpha)
\end{array}\right)
\end{array}\right) \\
\beta o f f\left(\begin{array}{c}
B A(k)=O w n(\beta) \\
\vee\left(\begin{array}{c}
B A(k)=O w n(\phi) \\
\Lambda B A(k+m)=O w n(\beta)
\end{array}\right)
\end{array}\right)
\end{array}\right.
$$

Here, $m$ and $n$ are the smallest natural numbers representing points at which ball possession is definite, descending in time. 


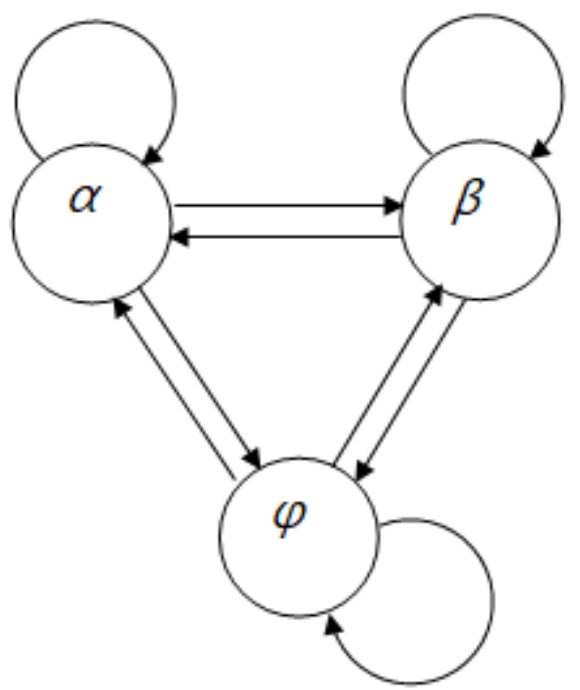

Figure8. Determinate FSM expressing ball possession

This yields the following FSM with the indeterminacy of states eliminated (Figure 9) from a determinate FSM (Figure 8) with the same form as the FSM expressing ball possession (Figure 6).

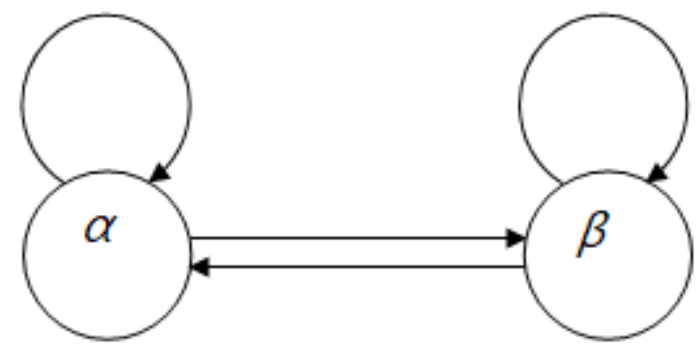

Figure9. FSM expressing offence modes with indefinite states eliminated

Furthermore, the sustained periods $t+1$ through $t+m$ appearing in transition states taking the form of a self-loop are expressed with time intervals $(t+1, t+m)$. The transition of state from $\alpha$ to $\beta$ at time $t$ can be illustrated as in Figure 10.

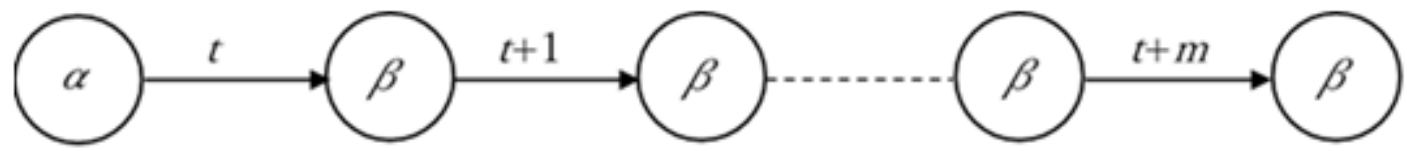

Figure 10. FSM representing the progression of a state transition in a self-loop

The relationship between $B A(k)$ and is $O f f(k)$ can be intuited as in Figure 11 below.

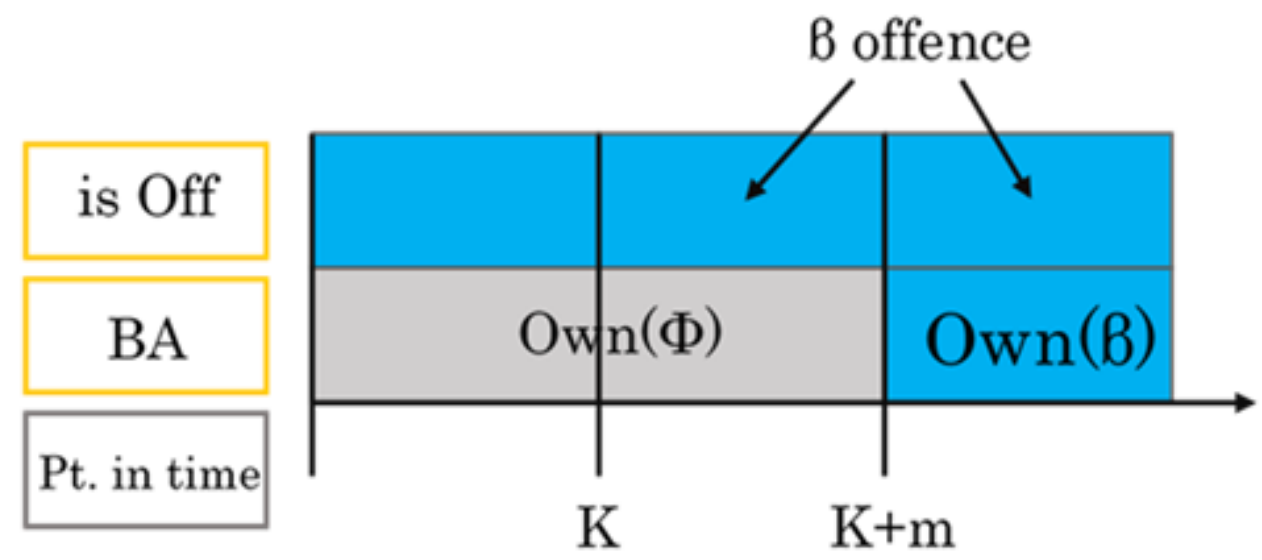

Figure 11. Relationship between $B A(k)$ and $i s O f f(k)$ 


\subsection{Offence/Defence Determinations and Bases for Them}

while team $\alpha$ For reference, let us outline the basis for eliminating indeterminacy through the aforementioned types of processes to establish determinacy.

First, even in cases when observers - and experts as well-are determining offence/defence status while watching a video recording of a football match, they may reserve judgment at particular moments in the match when determination cannot be made. At a subsequent point when it can be decided which team is attacking, they will consider teams' offence/defence status at this point to correspond to the offence/defence status at the point when judgment was reserved. In this study, the researchers take these periods when determination must be "reserved" to be periods when an indeterminate transition is taking place and record them as transitions of offence/defence status using a nondeterministic finite automaton (hereinafter "NFA").

Next, the subset construction theory of "regard[ing] multiple states occurring through transitions from a single state with the same input collectively as single states" (15) is applied to convert this NFA to a deterministic finite automaton (hereinafter "DFA"). If this application is restricted to offence/defence status in a football match, the resulting DFA will contain four states $(\varphi,\{\alpha\},\{\beta\},\{\alpha, \beta\})$ as there will be two teams $(\alpha, \beta)$ participating in the match.

Furthermore, although the DFA is deterministic, the $\varphi$ and $\{\alpha, \beta\}$ states (which are collectively represented as $\varnothing$ ) denote that determination of offence/defence status is being reserved. As transition progresses to a point in time when the determination of offence/defence status is fixed, a team's offence/defence status undergoes a transition to a fixed state. Accordingly, by rewriting transitions to the $\varnothing$ state as transitions to states in which a team's offence/defence status is fixed, it becomes possible to limit application to inter-state transitions of teams' fixed offence/defence statuses.

\section{Pass Extraction}

While one team is attacking, there will occur travel of the ball between players of that team, such as passing and dribbling. In this study, we have attempted to extract passes - which are considered to be vital in performing tactical analysis - from the data using the offence/defence model formulated above. Note that the only passes we deal with here are ones that have been successful. Passes are considered to occur when "shot" states persist for certain fixed intervals for teams in sustained offence mode. This means that in the following example, periods when the expression below is satisfied $(k+1$, $k+m)$ are judged to be individual passes occurringis in offence mode $(11,12)$.

$$
\text { Pass }=\left(\begin{array}{c}
i s O f f(k)=\alpha o f f \wedge i s O f f(k+m)=\alpha o f f \\
\wedge B C(k+1)=B C(k+2)=\cdots \\
=B C(k+m-1) \\
\text { shot }
\end{array}\right.
$$

Furthermore, when players participating in passes are the same before and after the pass, the pass is regarded as dribbling, and if they are not, it is regarded as passing.

The above outline represents the most basic components of pass extraction. Application of this process, or refinement of it, will enable the acquisition of more information with regard to passes (11).

In conjunction with pass extraction, information including the pass's starting position, ending position, distance, direction, the players participating in it and so on are obtained for each individual pass, yet this is all physical information obtained directly from location data.

Meanwhile, information obtained from the offence/defence model in conjunction with pass extraction includes series of passes occurring while a team is in offence mode, or in other words instances of successive passing. It is anticipated that this information in combination with the aforementioned physical information obtained in conjunction with pass extraction may yield information effective for tactical analysis.

Also, there are cases in which short passes could not be extracted with application of the shot constant defining the "shot" state that was used in structuring the FSM. For these cases, refining the model by revising the constant in accordance with the distance of ball travel in between players enabled extraction of shorter passes. 


\subsection{Results and Evaluation of Pass Extraction}

In this section, we will evaluate qualitative information obtained from the offence/defence model by comparing passes extracted through the offence/defence model with actual video footage data from a football match.

Passes can be obtained by applying the process of pass extraction outlined in the previous section based on times associated with offence/defence status (time elapsed since the kickoff, length of attack period, etc.) directly, using the offence/defence model (11).

First, when passes are extracted using the offence/defence model, various information associated with the passes is obtained, such as their number and the distance, direction, initiator and receiver for each individual pass. As such physical information does not have a direct relationship to the offence/defence model, methods of deriving this information will not be taken up here. Below are evaluations and considerations of what degree of extraction is possible for this pass-related information and what its degree of effectiveness is in comparison with information obtained from video recordings by manual means.

\subsection{Data Specifications}

The following data was used in this study (see Table 3):

Table3. Location data specifications

\begin{tabular}{|l|l|}
\hline Data & Hiroshima vs Yokohama \\
\hline Date & 2011.5 .14 \\
\hline Match & Sanfrecce Hiroshima vs Yokohama F. Marinos (1st half) \\
\hline Video & Full HD (1920x1080) \\
\hline \multirow{2}{*}{ Frame rate } & Video data: 30fps \\
\cline { 2 - 2 } & Location data: 5fps \\
\hline
\end{tabular}

The video was captured from a fixed position overlooking the playing field with a full view from above it at an angle. For tracking data, location coordinates for the players and ball were obtained by clicking on their respective positions on a frame-by-frame basis using video editing software. One point that sets this data apart from ordinary location data used on-site in sports is that location data for the ball was obtained in addition to location data for the players.

\subsection{Comparing the Results of Pass Extraction Using the Offence/Defence Model With Video of the Actual Match}

For the Hiroshima vs Yokohama match, the results of pass extraction obtained by applying the offence/defence model to this location data was compared with passes identified in the actual video recording of the match.

Values for $\operatorname{shot}_{b}$ (representing ball speed) and $r$ (the radius of close proximity to the ball), basic parameters of the offence/defence model, are outlined below in Table 4 along with the bases for their choice.

\begin{tabular}{|l|l|}
\hline shot $_{b}$ & Bases for ball speed settings \\
\hline $7.8 \mathrm{~m} / \mathrm{s}$ & $\begin{array}{l}\text { Represents a speed with which players would not be able to run fast enough to catch up, with } \\
\text { control of the ball in mind (12). Not used for pass extraction, however, as it allows only passes } \\
\text { with long distances. }\end{array}$ \\
\hline $7.3 \mathrm{~m} / \mathrm{s}$ & Enables extraction of passes with short distances. This value was applied for use (16). \\
\hline $5 \mathrm{~m} / \mathrm{s}$ & For comparison, represents a relatively fast pace on foot. \\
\hline$r$ & Bases for radii of close proximity to ball ${ }^{* 1}$ \\
\hline $2 \mathrm{~m}$ radius & $\begin{array}{l}\text { Represents a scope of movement that can be traveled in about 1 second while maintaining } \\
\text { possession of the ball. }\end{array}$ \\
\hline $1 \mathrm{~m}$ radius & $\begin{array}{l}\text { For comparison, represents the approximate radius of a circle formed by a player with both } \\
\text { arms stretched out, within which the player can be assumed to be in possession of the ball if } \\
\text { there are no other players within it. }\end{array}$ \\
\hline
\end{tabular}

*1 While in an actual game setting, the orientation of players' bodies may produce differences in their range of movement, the scope of close proximity is made a circle here, since the orientation of players' bodies is not recorded in the location data. 
To start out with, a total of 469 passes could be identified from the video recording of the match between Hiroshima and Yokohama, while 347 (142 for Hiroshima, 205 for Yokohama) were identified applying the offence/defence model with the parameters $s_{h o t}=7.3 \mathrm{~m} / \mathrm{s}$ and $r=2 \mathrm{~m}$ to the tracking data. For each of these passes, the researchers examined whether it was identified with the model or not, and whether it appeared in the video recording or not. Applying the offence/defence model using three additional sets of parameters - shot $_{b}=7.3 \mathrm{~m} / \mathrm{s}, r=1 \mathrm{~m} ;$ shot $_{b}=5.0 \mathrm{~m} / \mathrm{s}, r=2 \mathrm{~m}$; and shot $_{b}=5.0 \mathrm{~m} / \mathrm{s}, r=1 \mathrm{~m}$-yielded the following results, as shown in Table 5 below:

Table5. Comparison of passes obtained from the model and from the video recording

\begin{tabular}{|l|l|l|l|l|l|}
\hline \multirow{2}{*}{$\begin{array}{l}\text { Model parameters } \\
\text { Total no. of passes }\end{array}$} & shot $_{b}$ & $7.3 \mathrm{~m} / \mathrm{s}$ & $7.3 \mathrm{~m} / \mathrm{s}$ & $5.0 \mathrm{~m} / \mathrm{s}$ & $5.0 \mathrm{~m} / \mathrm{s}$ \\
\cline { 2 - 6 } & $r$ & $2 \mathrm{~m}$ & $1 \mathrm{~m}$ & $2 \mathrm{~m}$ & $1 \mathrm{~m}$ \\
\hline Video, Model $\circ$ & 347 & 251 & 328 & 288 \\
\hline Video $\times$, Model $\circ$ & 336 & 228 & 309 & 262 \\
\hline Video, Model $\times$ & 11 & 23 & 19 & 26 \\
\hline
\end{tabular}

For both Video and Model results, $\circ$ denotes that passes were identified and $\times$ denotes that they were not.

Precision and recall are calculated from the table above. Their meanings are defined as outlined below (see Table 6).

\begin{tabular}{|l|l|}
\hline Precision & $\begin{array}{l}\text { The ratio of passes extracted using the offence/defence model that actually appeared } \\
\text { in the video recording as well. An index related to accuracy. }\end{array}$ \\
\hline Recall & $\begin{array}{l}\text { The ratio of passes appearing in the actual video recording that were extracted using } \\
\text { the offence/defence model as well. An index related to completeness. }\end{array}$ \\
\hline
\end{tabular}

F-measure $\rightarrow$ The harmonic mean of precision and recall

Table6. Precision, recall and F-measure

As there is often a trade-off relationship between precision and recall, the F-measure is used as an index for comprehensive evaluation of accuracy and completeness, obtained with the following equation:

$$
F-\text { measure }=\frac{2 \cdot \text { prec } i \text { sion } \cdot \text { recall }}{\text { precision }+ \text { recall }}
$$

\begin{tabular}{|l|l|l|l|l|l|}
\hline \multirow{3}{*}{$\begin{array}{l}\text { Model parameters } \\
\text { Precision }\end{array}$} & shot $_{b}$ & $7.3 \mathrm{~m} / \mathrm{s}$ & $7.3 \mathrm{~m} / \mathrm{s}$ & $5.0 \mathrm{~m} / \mathrm{s}$ & $5.0 \mathrm{~m} / \mathrm{s}$ \\
\cline { 2 - 6 } & $r$ & $2 \mathrm{~m}$ & $1 \mathrm{~m}$ & $2 \mathrm{~m}$ & $1 \mathrm{~m}$ \\
\hline Recall & 0.97 & 0.91 & 0.94 & 0.91 \\
\hline F-measure & 0.72 & 0.49 & 0.66 & 0.56 \\
\hline
\end{tabular}

Table7. Precision and recall of pass identification

While, on the whole, recall levels are not high, within these results, the F-measure for the model with parameters shotb $=7.3 \mathrm{~m} / \mathrm{s}, \mathrm{r}=2 \mathrm{~m}$ is high, yielding results closer to what occurred in the actual match (see Table 7).

In addition, where passes were not extracted using the model while they did appear in the video recording - in other words, results represented as "Video $\circ$, Model $\times$ " in Table 5 - the reasons why passes were not identified using the model can be roughly categorized as in Table 8 below through verification with the video recording.

\begin{tabular}{|c|c|c|c|c|c|c|}
\hline & & \multicolumn{5}{|c|}{ Model parameters } \\
\hline & & $\operatorname{shot}_{b}$ & $7.3 \mathrm{~m} / \mathrm{s}$ & $7.3 \mathrm{~m} / \mathrm{s}$ & $5.0 \mathrm{~m} / \mathrm{s}$ & $5.0 \mathrm{~m} / \mathrm{s}$ \\
\hline Category & $\begin{array}{l}\text { Game } \\
\text { examples }\end{array}$ & $r$ & $2 \mathrm{~m}$ & $1 \mathrm{~m}$ & $2 \mathrm{~m}$ & $1 \mathrm{~m}$ \\
\hline One-touch pass & \multicolumn{2}{|c|}{$\begin{array}{l}\text { A player has made a pass with a } \\
\text { single touch }\end{array}$} & 42 & 36 & 38 & 39 \\
\hline Mêlée state & \multicolumn{2}{|c|}{$\begin{array}{l}\text { A complicated assortment of } \\
\text { players are in close proximity to } \\
\text { the ball }\end{array}$} & 39 & 34 & 40 & 27 \\
\hline
\end{tabular}




\begin{tabular}{|l|l|l|l|l|l|}
\hline $\begin{array}{l}\text { Coordinate } \\
\text { discrepancy }\end{array}$ & $\begin{array}{l}\text { Inaccurate values were obtained } \\
\text { during digitization of the video } \\
\text { recording }\end{array}$ & 33 & 29 & 28 & 23 \\
\hline Slow speed & Speed of ball movement is slow & 16 & 16 & 9 & 11 \\
\hline $\begin{array}{l}\text { Not in "shot" } \\
\text { state }\end{array}$ & $\begin{array}{l}\text { The video recording does not } \\
\text { show the ball in a "shot" state }\end{array}$ & 1 & 1 & 1 & 1 \\
\hline Angle & $\begin{array}{l}\text { A change in the ball's angle has } \\
\text { not been detected }\end{array}$ & 1 & 0 & 1 & 0 \\
\hline $\begin{array}{l}\text { Offence/defence } \\
\text { change }\end{array}$ & $\begin{array}{l}\text { Offence/defence status has } \\
\text { changed }\end{array}$ & 1 & 0 & 1 & 0 \\
\hline
\end{tabular}

Also, as can be understood referencing Table 8 above, no clear difference is apparent with thought to be the difficulty of identifying single touches with $5 \mathrm{fps}$ video and location data. Mêlée states, in the model, represent situations in which multiple players for opposing teams have control of the ball, and it is thought that, as interpreted by human observers, these often accompany changes in teams' offence/defence status. Regard to radius value $r$ representing the size of the circle considered "close proximity" to the ball. Accordingly, it can be conjectured that no simple resolution is offered by reduction of this $r$ value. Coordinate discrepancies, it is thought, result from the method of coordinate data acquisition.

\section{RESUltS AND DisCUSSION}

\subsection{Clarifying the Offence/Defence Model}

In this study, the researchers have attempted to provide a mathematical clarification of the offence/defence model with the application of FSM theory. This framework made it possible to mathematically model and clarify procedures for determining offence/defence status during sustained periods. In concrete terms, in the determination of offence/defence status at a particular point in time, there exists location data for 22 players plus the ball. However, as mathematical determination is ordinarily performed based on ball proximity or TRDRD information, in a sense it can be taken to represent the mathematical cutaway of a momentary cross-section for a certain point in time.

Takii (10) has stated, "The strategic/tactical proposition in world football concerns 'a synthesis of mobility and balance,' which is sought in 'continuity between offence and defence,' leaving no neutral ground between the two."

Such a strategic/tactical proposition denotes the existence of planning (10) in the backdrop of the game concerning how to economically and pertinently accomplish offence and defence objectives in the context of the 11-by-11-player sport. That is to say, accomplishing tactical analysis does not connote fragmentary analysis of individual points in time based on location data. On the basis of this concept, in performing technical analysis, mathematical understanding of game circumstances using FSMs as the background of mathematically-based technical determination regarding certain points in time, applying FSM theory, can be considered to make sense as a process for on-site technical evaluation of football playing.

Indeed, in Dutch football coaching, the following three key scenarios associated with the game are given, representing one perspective on discerning the makeup of the game with the objective of understanding:

1. Maintenance of ball possession by one's own team

2. Maintenance of ball possession by the opposing team

3. Transference of ball possession between teams (i.e. losing or gaining ball possession) (16).

In German football coaching as well, the following four scenarios have been given as the components structuring the game:

1. Offence mode

2. Offence-to-defence transition

3. Defence mode

4. Defence-to-offence transition (17). 
These models serve to convey the importance of distinguishing the different scenarios as a foundational approach for tactically grasping the circumstances of a game as they unfold in a sequence of events. That is to say, tactical analysis of the circumstances of a game entails performing tactical analysis of plays within the game to provide a foundation for discerning the different scenarios as they relate to the two teams.

While at any certain point in the game there exist 22 player states, tactical analysis using the mathematical model applied directly to the location data is made possible, based on determination of the team's situations (i.e. offence/defence statuses) through FSM theory. In the process of tactical analysis, there also exists the potential to perform analysis with regard to players in locations not in close proximity to the ball close to processes of analysis carried out by human observers. In attempting to provide mathematical clarification with the use of FSMs, this research has enabled contributions to be made to improving the quality of foundation-building for tactical analysis using a mathematical model applied directly to location data.

\subsection{Pass Extraction And Evaluation Of It}

In this study, the researchers performed pass extraction using the offence/defence model, attempting to provide mathematical clarification of it with the use of FSMs. Using the offence/defence model with the parameters outlined in Table 4 yielded the results shown in Table 5, demonstrating that it was, thus, possible to perform pass extraction using the model. However, as there were discrepancies between the number of passes identified in the actual video recording of the match and the number extracted using the mathematical model, the researchers performed a comparison of the circumstances surrounding passes identified in the actual video recording with those extracted using the model (see Table 5) - and additionally, cases in which passes that were extracted using the model also appeared as passes in the actual video recording.

With the derivation of precision as an index related to accuracy and recall as the ratio of passes appearing in the actual video recording that were identified using the offence/defence model, comparisons of each parameter set were performed based on the harmonic mean of precision and recall - their F-measure (see Table 7). While, on the whole, recall levels were not high, within those results, the F-measure was high for results yielded by parameters shotb $=7.3 \mathrm{~m} / \mathrm{s}, \mathrm{r}=2 \mathrm{~m}$. Due to the fact that while levels of recall were low for pass extraction using the offence/defence model, levels of precision were high, it was anticipated that the passes identified mostly did reflect actual passes. Still, with regard to the causes for passes not being extracted using the offence/defence model (i.e. for levels of recall being low overall), circumstances identified in the video recording that were considered to have prevented passes from being identified were examined as well (see Table 8).

It became clear that one-touch passes and mêlée states were the main causes, as judged from the circumstances of the game. A relevant detail with regard to one-touch passes is that, with its $5 \mathrm{fps}$ frame rate, the location data used captured data at 0.2 -second intervals. Considering the fact that an ordinary length of contact time between a player's foot and the ball when they make a kick is 0.01 seconds (18), it can be anticipated that fully capturing moments of impact between players' feet and the ball will be difficult or infeasible with these 0.2-second intervals. Accordingly, the frame rate used in this study can be considered to be a cause of difficulty in capturing one-touch passes in the data collected. With the pace of technological advancement seen in recent years, however, the level of precision in location data can be anticipated to be an area likely to see future improvement. Mêlée states, as determined with the model, correspond to situations in which multiple players for opposing teams have control of the ball, and even in interpretation by human observers watching the actual video recording, it is considered difficult to determine teams' offence/defence status at particular momentary points in time with such states.

Such circumstances in the game as these, viewed from a tactical perspective, can be considered areas likely to see improvement with refinement of the offence/defence model via the course of attempting to mathematically clarify the model with the use of FSMs. Also, from Table 8 it can be seen that no clear discrepancy between pass extraction totals is observed based on the size of value $r$ representing the radius of a circle considered "close proximity" to the ball, and so it is anticipated that resolution will not be offered by simply reducing the size of this $r$ value either.

It is also thought that the coordinate discrepancies result from the method of coordinate data 
acquisition used when constructing the location data. The method of coordinate data acquisition used for this study involved clicking on a computer display to manually enter coordinates from the video recording, yielding approximately 310,000 instances of coordinate data for the 90-minute football match. As mentioned above as well, it is anticipated that this is an area in which technological innovation will bring improvements.

With pass extraction attempted using an offence/defence model, it was possible to perform extraction directly from the location data using a mathematical model. With regard to recall, while it is anticipated that future technological innovation may possibly bring improvements, the model served as an appropriate framework for the pass extraction process. Through the use of this framework for pass extraction using an offence/defence model, it was possible to verify the development of tactical analysis applied directly to the location data using a mathematical model from basic tactical analysis based on determination of offence/defence status to a framework capable of tactical analysis encompassing the addition of the ball's state in the form of passes.

\section{CONCLUSION}

In this research effort, the researchers have attempted to further clarify the existing offence/defence model for football with a mathematically-based tactical analysis model incorporating FSM theory. Through the application of mathematical models to the process for determining teams' offence/defence status, it was possible to reconstruct the process as a mathematical model with the capacity to determine offence/defence status from location data on the basis of a mathematical process. Furthermore, the researchers were able to construct the mathematical model as a determination process corresponding to tactical judgment processes made by individuals watching football playing or training in person as well. Also, in determinations made by the mathematical model, we were able to mathematically construct a process for making determinations for certain points in time based on grasping a team's situation regarding offence/defence status in the context of the game rather than making fragmentary determinations for certain time points. It is anticipated that this may lead to qualitative improvements in tactical analysis using mathematical models in the future.

Also, in this study, we attempted to perform pass extraction using the mathematically clarified offence/defence model. In performing pass extraction directly from location data, future efforts to make improvements with regard to recall in ball-passing situations will need to be made. As far as the main cause for this, it became clear that improvements are needed regarding the frame rate and resolution of the data and video recordings, and we were able to conclude that qualitative improvements regarding location data collection and video recording technology are to be anticipated in the future. With regard to passes extracted using the model, we were able to confirm that they did reflect actual circumstances occurring in the game, meaning that use of the offence/defence model enabled passes made by the attacking team to be identified directly from the data. It is thought that being able to determine offence/defence status and passes using a mathematical model will help advance analysis of teams' tactical behavior as well.

The results of this study suggest the potential of using mathematical models to perform tactical analysis directly from location data. Customarily with in-person tactical analysis of game circumstances, however, observers' interpretations are made against the backdrop of their own experience, which presents extremely difficult questions regarding guarantees of objectivity. It is already, in the first place, difficult to affirm the uniformity of tactical interpretations regarding football games, so the results derived from tactical analysis relying on the use of location data, mathematical models and so on must not be viewed as set "answers" with regard to game circumstances.

In our view, such results can, in a sense, be considered to represent a sort of starting line for discussions regarding the circumstances of a game at a certain given moment, providing reference points for discussions by multiple observers as they find their way toward consensus, which would be the essential factor here.

With tactical analysis using a mathematical model applied to location data, while there do presently exist limits to the level of objectivity that can be ensured, as discussed above, depending on the approach taken in making use of it, it also has the potential, we feel, to make contributions to tactical development in football in the future. The shifts and developments that have taken place in the 
evolution of football tactics have been brought about by the interplay of many multiple parties involved with the sport - the players, coaches, spectators and so on-along with the cumulative succession of discussions that have taken place with regard to the way the sport is played. The shifts and developments in football tactics' evolution have, in other words, been achieved dialectically, facilitated by the cumulative succession of plays that have been made and of the diverse range of tactical analyses that have been applied to football games' circumstances (19).

Also, in order to bring the course of tactical development in football to its full realization, the boosting of coach leadership quality to the next level can be taken to be an essential element. In recent years, systems for training coaches in nations leading in the sport of football have incorporated approaches based in social constructivist theory in their formulation (20). To incorporate social constructivist approaches means formulating coach training systems based on the perspective that football's culture and social community play substantive roles in knowledge construction (21). As touched on above, taking into account the tactical shifts occurring in football, which have developed dialectically, perceiving the very activity of training coaches, within the coach training framework, as an activity concerned with knowledge construction in football's culture and social community should make it possible to deem the effort a sensible one with regard to the shifting evolution of football tactics.

Cushion (22), furthermore, has expounded on the importance of reflection and mentoring facilitated by coaches in the role of tutors with rich bases of coaching experience as well as by course-trainee coaches, in activities concerned with coach training via social constructivist approaches. Webb and Leader (23), in addition, have also made reference to the necessity of discussions made involving critical tutors with learning in the form of coach training, along with the necessity of the future utilization of objective data. Though changes in trainees' disposition through discussion-mediated tutoring can be confirmed, this is an indication of the consciousness that an awareness gap exists with regard to tactical knowledge (23), meaning this is also an allusion to the necessity of making use of objective data in the future as a resource for bridging this gap. Taking this sort of necessity into account as well, along with the construction of a coach training system facilitating reasonable learning with regard to shifts in the evolution of football tactics, the mathematical model dealt with in this study can be considered to hold meaningful significance for the future in the utilization of objective data as a resource for actualizing tactical development in football through the construction of such a system. It is extremely significant that a course with singular directionality was indicated with regard to the question of how to utilize tactical analysis using big data and AI technologies, which are expected to see rapid growth looking forward.

Up until now, football's development has involved people's use of their bodies, with the cumulative succession of plays made by human players and feedback on those plays structured in an economical and pertinent way by people. It is imperative to now place modern big data (and the various technologies that make use of it) as tools to facilitate this work of economical and pertinent structuring. With big data (and the various technologies that make use of it), it can be anticipated that maintaining the involvement of people who play sports as the central actors will enable further development without the sacrifice of any of the many charms that have traditionally been associated with sports. Having made one affirmation of a fusion of the charms associated with sports and the usefulness of big data (and the various technologies that make use of it), it is our hope that the efforts we have made with this research may be of some assistance in advancing the field of tactical development — one of the many charms associated with sports - through work carried out by people in the days ahead.

\section{REFERENCES}

[1] Kakemizu Takashi and Ōhashi Jirō. Sakkāomoshiro-kagaku: Gēmu ni motozuita gōriteki-na renshū[Football: Interesting Science - Rational Practice Based on Scientific Analysis of the Game]. Tokyo: Tokyo Denki University Press, 1996.

[2] Katō Kenta. Sakkāni okeru dēta to chīmu kyōka [Data and Team Improvement in Football]. IEICE Communications Society Magazine, vol. 10, no. 1, 2016, pp. 29-34.

[3] Narizuka Takuma and Yamazaki Yoshihiro. Doronē bunkatsu to kaisō-teki kurasutaringu wo mochiita shūdan supōtsu ni okeru fōmēshon kaiseki shuhō no teian (Tokushū: Supōtsu tōkei kagaku no arata-na chōsen) [Proposal for a Technique of Analyzing Formations in Team Sports Using Delaunay Division and Hierarchical Clustering (Special Feature: New Challenges in Sports-Related Statistical Science)]. Proceedings of the Institute of Statistical Mathematics, vol. 65, no. 2, 2017, pp. 299-307. https://ci.nii.ac.jp/naid/120006727373/. 
[4] Kamiya Keita, Nakanishi Wataru, Izumi Yūichirō. Torakkingu dēta wo mochiita sakkā no shiai ni okeru senkyō henka no chūshutsu [Extraction of Changes in the State of Competition in Football Matches Using Tracking Data]. Proceedings of the Institute of Statistical Mathematics, vol. 65, no. 2, 2017, pp. $287-298$. https://doi.org/10.1016/j.procs.2019.01.106\%0A, https://doi.org/10.1016/j.apenergy.2019.114422\%0A, http://dx.doi.org/10.1016/j.ijfatigue.2008.11.016\%0A, http://www.ansr.pt/Estatisticas/RelatoriosDeSinist ralidde/Pages/default.aspx\%0A, http://dx.doi.org/10.1016/j.

[5] Jo Hirotaka, Ōsawa Keisuke, Mishio Shōta, Andō Kozue, Suzuki Kōya, Nishijima Takahiko. Sakkā no kōgeki ni okeru purē no saitekika arugorizumu no kaihatsu (Tokushū: Supōtsu tōkei kagaku no arata-na chōsen) [Development of Optimisation Algorithms for Plays in Football Offence (Special Feature: New Challenges in Sports-Related Statistical Science)]. Proceedings of the Institute of Statistical Mathematics, vol. 65, no. 2, 2017, pp. 309-321. https://ci.nii.ac.jp/naid/120006727374/.

[6] Tsuchida Jun and Yadohisa Hiroshi. Jūryoku moderu wo mochiita sakkā senshu no ugoki no teiryōka (Tokushū: Supōtsu tōkei kagaku no arata-na chōsen) [Quantification of Football Players' Movement Using the Gravity Model (Special Feature: New Challenges in Sports-Related Statistical Science)]. Proceedings of the Institute of Statistical Mathematics, vol. 65, no. 2, 2017, pp. 271-286. https://ci.nii.ac.jp/ naid/120006727371/.

[7] Tamura Yoshiyasu and Sakaori Fumitake. "Tokushū: Supōtsu tōkei kagaku no arata-na chōsen" ni tsuite. [Regarding the "Special Feature: New Challenges in Sports-Related Statistical Science"]. Proceedings of the Institute of Statistical Mathematics, vol. 65, no. 2, 2017, pp. 183-184. http://www.ism.ac.jp/ editsec/toukei/pdf/65-2-183.pdf. Accessed 31 January 2019.

[8] Yamanaka Akira, Ōtsuka Hiroshi, Deguchi Tatsuya, Okihara Ken, Ōtsuka Dōta, Uchida Shinya, Jorge Diaz-Cidoncha Garcia, Selina Khoo, David Stroud, Sugiyama Masahiro. Tactical Analysis Through Objective Data in Football. Insight - Sports Science, vol. 2, no. 1, 2020, pp. 1-15. http://insight.piscomed.com/index.php/ ISS/article/view/257/. Accessed 23 April 2020.

[9] Wade, Allen. Ingurando: Sakkā kyōtei [England - Football Curriculum]. Tokyo: Baseball Magazine Sha, 1973. p.5.

[10] Takii Toshirō. Wārudo sakkā no senjutsu [Tactics of World Football]. Tokyo: Baseball Magazine Sha, 1995.

[11] Satō Yūsuke, Yamanaka Akira, Ōtsuka Hiroshi. A-017: Sakkā no kōshu suii no moderu kara no pasu no chūshutsu (A bunya: Moderu/arugorizumu/puroguramingu, ippan ronbun). [A-017: Pass Extraction from an Offence/Defence Model for Football (Division A: Models/Algorithms/Programming and General Papers)]. Forum on Information Technology, vol. 14, no. 1, 2015, pp. 145-148. https://ci.nii.ac.jp/ naid/110009988576/.

[12] Iwasa Mahoto. Time-Restricted Dominant Region Diagram for Analysing Soccer Defence. MS thesis, Ehime University Graduate School of Science and Engineering, 2012.

[13] Yamanaka Akira and Ōtsuka Hiroshi.Jikan seigen-tsuki yūsei ryōiki-zu ni yoru sakkāno kōshu suii no moderu kōchiku[Construction of a Time-Restricted Dominant Region Diagram-Based Offence/Defence Model for Football]. 19th Research Association of Statistical Sciences Symposium, 2014.

[14] Yamanaka Akira and Ōtsuka Hiroshi. Jikan seigen-tsuki yūsei ryōiki-zu ni yoru sakkā no kōshu suii moderu no hyōka [Evaluation of a Time-Restricted Dominant Region Diagram-Based Offence/Defence Model for Football]. Proceedings of the 77th Japan Annual Convention, 2015, pp. 407-408.

[15] Kobuchi Yōichi. Risan jōhō shori to ōtomaton [Discrete Information Processing and Automatons]. Tokyo: Asakura Publishing, 1999.

[16] Royal Dutch Football Association. Oranda no sakkā senshu ikusei puroguramu: Junia/yūsu-hen - Nenreibetsu/pojishon-betsu shidōhō to renshū puroguramu[Dutch Football Player Training Programme: Junior/Youth Edition - Age-Specific, Position-Specific Coaching Methods and Practice Programme]. Tokyo: Taishukan Publishing, 2003.

[17] Tsuchiya Keita. Doitsuryū sakkā raisensu kōza: "Sekai ōja" ga akasu jissen-teki torēningu riron - Ejiru, Myurā, Gettse, Kurōsu... Karera wo sodateta Doitsu-ryū no shidōjutsu to wa.[German Football License Course: "World Champion"-Divulged Practical Training Theory — Özil, Müller, Götze, Kroos... On the Coaching Techniques that Fostered Them]. Tokyo: Baseball Magazine Sha, 2015.

[18] Asai Takeshi and Nunome Hiroyuki. Mikata ga kawaru sakkā saiensu [Perception-Changing Football Science]. Tokyo: Iwanami Library of Science, 2002.

[19] Tawa Takeo. Sakkā no kōchingu (Gendai supōtsu kōchi zenshū) [Football Coaching (Modern Sports Coaching Collection)]. Tokyo: Taishukan Publishing, 1974.

[20] Chapman, Reece, Dave Richardson, Ed Cope, Colum Cronin. Learning from the Past; A Freirean Analysis of FA Coach Education Since 1967. Sport, Education and Society, vol. 25, no. 6, 2020, pp. 681-697. https://doi.org/10.1080/13573322.2019.1654989/. 
[21] Nakamura Keiko. Kōseishugi ni okeru manabi no riron: Shinrigaku-teki kōseishugi to shakai-teki kōseishugi wo hikaku shite [Theories of Learning in Constructivism: Comparing Psychological Constructivism with Social Constructivism]. Bulletin of Niigata Seiryo University, vol. 7, no. 7, 2007, pp. 167-176.

[22] Cushion, Christopher J., Kathy M. Armour, Robyn L Jones. Coach Education and Continuing Professional Development: Experience and Learning to Coach. Quest, vol. 55, no. 3, 2003, pp. 215-230. https://doi.org/10.1080/00336297.2003.10491800.

[23] Webb, Keith, and Thomas M. Leeder. Dispositions and Coaching Theories: Understanding the Impact of Coach Education on Novice Coaches' Learning. Sport, Education and Society, 2021, pp. 1-14. https://doi.org/10.1080/13573322.2021.1887846/.

Citation: Jorge Diaz-Cidoncha Garcia, et.al. "Evaluation of Football Pass Extraction Using the Offence/Defence Model" International Journal of Sports and Physical Education (IJSPE), vol 7, no. 1, 2021, pp. 19-35. doi: https://doi.org/10.20431/2454-6380.0701004.

Copyright: (c) 2021 Authors. This is an open-access article distributed under the terms of the Creative Commons Attribution License, which permits unrestricted use, distribution, and reproduction in any medium, provided the original author and source are credited. 